\title{
Retinoids repress Ah receptor CYP1A1 induction pathway through the SMRT corepressor
}

\author{
Frédérique Fallone $^{1}$, Pierre-Henri Villard ${ }^{1}$, Eric Sérée ${ }^{1}$, Odile Rimet ${ }^{1}$, Quock Binh \\ Nguyen $^{1}$, Véronique Bourgarel-Rey ${ }^{1}$, Francis Fouchier ${ }^{1}$, Yves Barra ${ }^{1}$, Alain Durand ${ }^{2}$, \\ and Bruno Lacarelle ${ }^{1^{*}}$
}

${ }^{1}$ FRE CNRS 2737 and ${ }^{2}$ Laboratoire de Toxicologie, Faculté de Pharmacie, Université de la Méditerranée, 27 Bd Jean Moulin, 13385 Marseille Cedex 05, France

* Corresponding author

FRE CNRS 2737, Faculté de Pharmacie, 27 Bd Jean Moulin, 13385 Marseille cedex 5, France.

Telephone: +33-4-91-83-56-08

Fax: +33-4-91-83-56-08

E-mail address: bruno.lacarelle@ pharmacie.univ-mrs.fr 


\section{ABSTRACT}

CYP1A1 is mainly regulated by AhR and to a lesser extent by RAR. In our environment, we are exposed to AhR and RAR ligands, but little is known concerning the effect of a such coexposure. Using Caco-2 cells, 3MC and RA are respectively strong and weak CYP1A1 inducers. We showed that CYP1A1 induction of cells coexposed with 3MC and RA is significantly lower compared with cells exposed to $3 \mathrm{MC}$ alone (enzymatic activity, mRNA, promoter activity). We further showed that RA slightly decreased AhR protein level. By using cells transfected with the corepressor SMRT, and coimmunoprecipitation experiments, we demonstrated a marked physical interaction between AhR and SMRT when cells were treated with $3 \mathrm{MC}$ and $\mathrm{RA}$, compared to $3 \mathrm{MC}$ alone, thus explaining the decrease of CYP1A1 induction. In conclusion, we described a new mechanism involved in CYP1A1 regulation: retinoids decrease CYP1A1 induction related to the AhR pathway through the RAR corepressor SMRT. 
Numerous studies widely support that environmental factors influence carcinogenesis [1]. Among them, procarcinogens such as heterocyclic amines (HAs) and polycyclic aromatic hydrocarbons (PAHs) are inert on their own and require bioactivation into electrophilic metabolites to exert their genotoxic effects, generally localized at the site of expression of bioactivation enzymes, like cytochromes P450 (CYPs). CYPs, that metabolize a wide range of compounds of both endogenous (steroids, prostaglandins...) and exogenous origin, plays a major role in these bioactivation processes [2] [3]. In humans, CYP1A1, expressed in extrahepatic tissues including colon [4], is largely involved in the bioactivation of PAHs and HAs. Variation of CYP1A1 expression can therefore modulate cell susceptibility to procarcinogen exposures. This isoform is mainly regulated by aryl hydrocarbon receptor $(\mathrm{AhR})$ a transcription factor that functions as a ligand-activated receptor [5]. Following ligand binding in the cytoplasm, AhR is internalized and dimerizes with the Ah-receptor nuclear translocator (Arnt). This heterodimer acquires the ability to interact with xenobiotic responsive elements (XREs), which enhances transcription of CYP1A1 gene. However, nuclear receptors (NR) are also involved in CYP1A1 regulation: low doses of retinoic acid (RA), a natural vitamin A metabolite, slightly induces cutaneous CYP1A1 expression, by activation of RAR-RXR (retinoic acid receptor/retinoid X receptor) heterodimer bound on the RA responsive element (RARE) sequence located within the CYP1A1 promoter [6]. Many carotenoids (alpha and beta-carotene, beta-cryptoxanthin), in part contained in food, can be metabolized into products with retinoid activity and then activate CYP1A1 through this signaling pathway [7]. Several studies have demonstrated that the activity of members of the NR superfamily is dependent on interactions with other proteins, including a large number of coactivators and corepressors that are important tissue/cell-specific mediators of NR function [8] [9]. Indeed, unliganded RAR can interact with two different corepressors, N-CoR (nuclear receptor corepressor) or SMRT (silencing mediator for retinoid and thyroid hormone 
receptors) [10], which form large protein complexes including histone deacetylases (HDACs), which specifically affect the accessibility and/or function of transcriptional regulatory proteins that bind DNA sequences, triggering the inhibition of gene [11]. The regulation of the CYP1A1 gene expression by single compounds have been extensively investigated. Nevertheless, we are everyday exposed to a set of environmental pollutants, and little is known about the effects of an exposure to several toxicants on organism targets such as drug metabolizing enzymes. For example, exposure to mixtures of halogenated aromatic compounds frequently leads to non additive responses suggesting a possible competition for AhR binding [12] [13]. The aim of our study was therefore to investigate the effect of a coexposure with 3-methylcholanthrene, a PAH, and RA on CYP1A1 in a human colorectal adenocarcinoma Caco-2 cell line. 


\section{Materials and Methods}

Chemicals. All chemicals were obtained from Sigma except for all-trans-retinoic acid (RA) and dimethyl sulfoxide (DMSO) obtained from Acros Organics, $\beta$-mercaptoethanol obtained from Merck Eurolab, Dnase I, RNase-free and Protein G-agarose, obtained from Roche diagnostics.

Cell Culture. The human colorectal adenocarcinoma Caco-2 cell line [14] was a generous gift from Dr. A. Le Bivic (Faculté des Sciences de Luminy, Marseille, France). The cells were routinely maintained in an atmosphere at $37^{\circ} \mathrm{C}$ and $9 \% \mathrm{CO}_{2}$, with a standard culture DMEM (Dubelcco's modified Eagle's medium) medium, supplemented with 15\% foetal bovine serum (FBS) (Eurobio), 2mM L-glutamine, 1\% non essential amino acids and $100 \mathrm{IU} / \mathrm{ml}$ penicillin and $100 \mu \mathrm{g} / \mathrm{ml}$ streptomycin (Life technologies).

Cell treatment. As soon as Caco-2 cells reached confluence, they were starved for $24 \mathrm{~h}$ without serum since CYP1A1 mRNA level is transiently increased by FBS [15]. Treatments were conducted for $12 \mathrm{~h}$ with $0.1 \%$ DMSO, or $1 \mu \mathrm{M}$ RA, or $10 \mu \mathrm{M} 3 \mathrm{MC}$, or $10 \mu \mathrm{M} 3 \mathrm{MC}$ plus $1 \mu \mathrm{M}$ RA. All manipulations involving RA were performed in a dark room under dim yellow light to prevent photoisomerization. Concerning trichostatin A (TSA) exposure, cells were preincubated for $12 \mathrm{~h}$ with $300 \mathrm{nM}$ TSA, then exposed as described above, in addition with TSA. Optimal doses of treatments with RA, 3MC and TSA were defined during preliminary experiments (data not shown).

CYP1A1 enzymatic activity. Cell exposures were as previously described, for $24 \mathrm{~h}$. Ethoxyresorufin-O-Deethylase (EROD) activity, mainly supported by CYP1A, was determined according to the Burke et al. method [16], slightly modified by Kennedy et al. [17]. EROD activity was calculated as pmol of resorufin/mg total cellular protein/min activity 
expressed as a percentage of control. Total protein amount was determined by the Bradford method [18] using bovine serum albumin as the standard.

Quantitative expression of CYP1A1 mRNA by real time RT-PCR. Total cellular RNA were prepared with High Pure RNA isolation Kit (Roche diagnostics). One $\mu$ g of total RNA was reverse-transcribed using M-MLV reverse-transcriptase (Invitrogen) in its own buffer and random primers (Biolabs). The PCR reaction was carried out using the LightCycler System and the Faststart DNA master SYBRGreen I Kit (Roche diagnostics). $\beta 2$ microglobulin $(\beta 2 \mathrm{~m})$ was used as the internal standard. The $\mathrm{MgCl}_{2}$ concentration was set at $5 \mathrm{mM}$ and the primers $(0.25 \mu \mathrm{M})$ used for CYP1A1 and $\beta 2 \mathrm{~m}$ amplification were:

$\begin{array}{ll}\text { CYP1A1 (Sense) } & \text { 5' AAGAGGAGCTAGACACAGT 3' } \\ \text { CYP1A1 (Antisense) } & \text { 5' GAAACCGTTCAGGTAGGA 3' } \\ \beta 2 \mathrm{~m} \text { (Sense) } & \text { 5' CCGACATTGAAGTTGACTTAC 3, } \\ \beta 2 \mathrm{~m} \text { (Antisense) } & \text { 5' ATCTTCAAACCTCCATGATG 3, }\end{array}$

Cycling conditions were as follows: 10 min denaturation at $95^{\circ} \mathrm{C}$, followed by 45 cycles with 10-s denaturation at $95^{\circ} \mathrm{C}, 8$-s primer annealing at $55^{\circ} \mathrm{C}$ and 8 -s of elongation at $72^{\circ} \mathrm{C}$. The LightCycler was programmed to carry out a melting cycle to verify the specificity of the desired products. Melting curves and quantitations were analyzed with the LightCycler and Rel Quant softwares respectively.

Transfection and CAT activity Assay. Cells in 6-well plates were grown to 50\% confluence before transient transfection performed by lipofection (Lipofectin ${ }^{\circledR}$ reagent, Invitrogen). The pRNH25c plasmid, kindly provided by Pr. R. Hines (Medical College of Wisconsin, Milwaukee, WI) [5], contains the bacterial chloramphenicol acetyltransferase (CAT) reporter gene, under the control of the -1140 to +309 promoter region of the human CYPIAl gene. We cotransfected $1.5 \mu \mathrm{g}$ of $\mathrm{pRNH} 25 \mathrm{c}$ with $0.5 \mu \mathrm{g}$ of $\beta$-galactosidase $(\beta$-gal) plasmid, kindly provided by Pr. S. Champion (FRE CNRS 2737, Marseille, France) and used as an internal 
standard. At confluence, cell exposures were as previously described, then incubated for $24 \mathrm{~h}$ with normal growth medium without FBS. The CAT protein level was determined using the CAT Elisa Kit (Roche diagnostics). The results were determined as relative CAT expression, corresponding to the pmol of CAT protein per $\mathrm{mg}$ of total proteins normalized to $\beta$-gal activity. The expression plasmid pCMX-SMRT was kindly provided by Dr. R. Evans (Salk Institute, La Jolla, CA) [19]. Transient cotransfections were carried out as described above, using $1.5 \mu \mathrm{g}$ of pRNH25c and increasing amounts of pCMX-SMRT. We verified, by immunofluorescence staining, that the SMRT level was greatly enhanced in SMRTtransfected cells (data not shown). We also used the XRE-TK-CAT plasmid, that confers 3MC responsiveness upon the tyrosine kinase (TK) promoter and adjacent CAT gene. XRETK-CAT only contains two consensus XRE sequences (underlined) (5'CCGCCCAAGCTTCCCCCCTCGCGTGACTGCGAGGGGAAGGAGGCGTGGCCACAC GTCTAGACTAGC-3') into the HindIII/XbaI sites, immediately upstream of the TK promoter in the pBL-CAT2 plasmid. Cells were cotransfected with $1 \mu \mathrm{g}$ XRE-TK-CAT and 0 or $2 \mu \mathrm{g}$ pCMX-SMRT as described above. At confluence, for pRNH25c/SMRT and XRE-TKCAT/SMRT cotransfections, cells were exposed with $0.1 \%$ DMSO or with $10 \mu \mathrm{M} 3 \mathrm{MC}$ for 12h. The results were determined as relative CAT expression which corresponds to the pmol of CAT protein per mg of total proteins.

Evaluation of AhR protein level by Western blot. Total cellular protein extracts were prepared by incubation with lysis buffer (2.5\% sodium dodecyl sulfate, $5 \%$ mercaptoethanol, $10 \%$ glycerol and $62.5 \mathrm{mM}$ Tris $\mathrm{HCl} \mathrm{pH} 6.8$ ). The protein concentration was determined as described above. Lysates were submitted to gel migration on SDS-PAGE, and transfered to nitrocellulose membranes. Immunoblotting was performed using anti-AhR polyclonal IgG (Santa Cruz Biotechnology), then exposed with Horseradish peroxydase-conjugated secondary antibody and visualized with chemoluminescence reagent (Amersham). The 
membrane was then stripped and rehybridized with a actin antibody (Sigma) for loading control.

Coimmunoprecipitation assays. Cells were exposed with $3 \mathrm{MC}$ alone or with RA for $1 \mathrm{~h}$. Cells transfected with pCMX-SMRT $(2 \mu \mathrm{g})$ and exposed with $3 \mathrm{MC}$ for $1 \mathrm{~h}$ were used as positive control. Immunoprecipitation (IP) experiments were performed using nuclear cell extracts of Caco-2 cells, prepared as previously described [20]. 400 $\mu \mathrm{g}$ nuclear proteins for each IP were incubated with DNAse I $(1 \mathrm{mg} / \mathrm{ml})$, then suspended in IP buffer (1\% Triton X100, 200mM sodium chloride, 20mM Tris pH8, 1mM EDTA, 10mM sodium fluoride, 10mM sodium pyrophosphate, $1 \mathrm{mM}$ orthovanadate and protease inhibitor cocktail). The extracts were precleared by mixing with $50 \mu \mathrm{l}$ protein G-agarose beads for $1 \mathrm{~h}$ at $4{ }^{\circ} \mathrm{C}$ and beads were removed by centrifugation for $2 \mathrm{~min}$ at $500 \mathrm{xg}$. The resulting supernatants were incubated with $2.5 \mu \mathrm{g}$ of anti-SMRT antibody overnight at $4{ }^{\circ} \mathrm{C}$. Immunoprecipitates were collected by incubation with protein G-agarose for $4 \mathrm{~h}$ and centrifugation for $2 \mathrm{~min}$ at $500 \mathrm{x} \mathrm{g}$. The pellets were then washed extensively with PBS. Beads with immunoprecipitates were suspended in loading buffer and analyzed by Western blotting. Anti-AhR polyclonal IgG were used as described above.

Statistical analysis. All experiments were repeated at least three times to ensure reproducibility. Means \pm SEM were calculated for each group. Statistical significance was determined using the ANOVA test with repeated measures and the ANOVA test with contrast analysis ( $p<0.05$ was considered as significant). 


\section{RESULTS AND DISCUSSION}

We first compared the effects of exposures with RA and/or 3MC on CYP1A1 expression. The EROD activity in Caco-2 cells treated with $1 \mu \mathrm{M}$ RA or $10 \mu \mathrm{M} 3 \mathrm{MC}$ was significantly increased, 3.5- $(p<0.001)$ and 7.9-fold $(p<0.001)$ respectively. Co-treatment with RA and $3 \mathrm{MC}$ led to statistically significant lower induction $(5.8$-fold, $p<0.001)$ of activity as compared with 3MC alone (Fig. 1A). Concerning transcript levels, we showed a slight (1.8fold; $p<0.01)$ and a marked (23-fold; $p<0.001)$ increase of CYP1A1 mRNA after RA and 3MC treatments respectively (Fig. 1B). After 3MC and RA co-treatment, we observed a significant decrease on CYP1A1 transcript induction as compared with 3MC alone (-55\%, $p<0.001)$. In order to further examine RA and 3MC effects on CYP1A1 promoter activity, cells were transiently transfected with $\mathrm{pRNH} 25 \mathrm{c}$ construction. As previously observed for mRNA and EROD activity, RA and 3MC significantly induced CYP1A1 promoter activity as compared with control cells (1.5-fold; $p<0.01$ and 3.6-fold; $p<0.001$, respectively) (Fig. 1C). A co-treatment significantly attenuated by $30 \%(p<0.01)$ the CAT increase relative to $3 \mathrm{MC}$ alone. These results show that RA exerts a repressive effect toward 3MC-induced CYP1A1 expression.

To elucidate the mechanism implied in this repression, we next studied the effect of $3 \mathrm{MC}$ and/or RA treatments on AhR level. Western blot analysis showed that addition of $10 \mu \mathrm{M}$ 3MC did not significantly modify the AhR protein amount, as compared with control cells

(Fig. 2). However, a treatment with $1 \mu \mathrm{M}$ RA alone or in combination with $3 \mathrm{MC}$ triggered a large decrease of AhR protein levels ( $-41 \%$ and $-49 \%$ respectively). The decrease of AhR level by RA could explain, at least in part, the decrease of 3MC-induced CYP1A1 expression. Therefore, RAR can directly or indirectly modulate AhR transcription by modifying signal transduction pathways. Even if interactions between RAR and AhR remain unclear and must 
be thoroughly studied, numerous studies conclude to a link between these two signaling pathways [2] [21].

We next wanted to find out if, in addition to the AhR expression decrease, the repression could involve a corepressor action. As corepressors need the recruitment of a complex harbouring histone deacetylase activity, we examined the involvement of HDACs on CYP1A1 induction, using TSA, a specific HDACs inhibitor [22]. When cells were exposed with TSA alone, an increase of basal CYP1A1 mRNA transcript was observed (Fig. 3). In the same way, TSA cotreatment enhanced the inductive effect of RA and 3MC (5.2- and 1.5-fold respectively), as compared to TSA unexposed cells. Similarly, Xu et al. [23], showed in cultured rat hepatocytes that TSA potentiated the effect of various concentrations of TCDD on EROD activity. Interestingly, we found in cells exposed with TSA, 3MC and RA, an additive effect of these inducers on CYP1A1 mRNA (2.8-fold). These data strengthened the involvement of a corepressor in the repressive effect of RA toward CYP1A1 induction by $3 \mathrm{MC}$.

In the last past years, many studies have shown that transcription cofactors/adapters, with no specific DNA-binding affinity, were important components of transcriptional regulation. Moreover, the AhR signal transduction pathway has recently been shown to be modulated by several nuclear cofactors [24] [25] [26]. Some of these coregulators can exert their activities on both AhR and RAR. Nguyen et al. [9] and Rushing and Denison [26] have previously shown a physical and functional interactions of the AhR complex with the RAR-corepressor SMRT, using in vitro transcribed/translated proteins. So, we subsequently investigated the involvement of the corepressor SMRT in the RA repressive effect toward CYP1A1 induction by 3MC. We first checked, using RT-PCR and Western blot experiments, that SMRT was expressed in Caco-2 cell line (data not shown). We then used cells transfected with both pRNH25c (Fig. 4A) and increasing amounts of SMRT cDNA. In untreated cells, we observed 
that the transfection of SMRT reduced in a dose-dependent manner the basal activity of CYP1A1 promoter, as reflected by the levels of reporter gene product CAT (Fig. 4B, top). These data were in agreement with the implication of AhR in CYP1A1 basal expression, since its transcription requires the binding of $\mathrm{AhR}$ on at least one XRE site (referencer Whitlock). Furthermore, our experiments with 3MC-treated cells showed that SMRT repressed the activation of CYP1A1 promoter induced by AhR activation. Indeed, in Fig. 4B (bottom), our results, presented as ratio CAT activity of 3MC-treated cells/CAT activity of untreated cells, showed a significant decrease of induction $(p<0.001)$ that paralleled with the increase of transfected corepressor (3.7-fold induction without SMRT cDNA versus 1.5 -fold with $2 \mu \mathrm{g}$ of SMRT cDNA). Accordingly with Nguyen et al. [9], we observed a variable inhibitory response at higher concentrations of SMRT $(3 \mu \mathrm{g})$ (data not shown). However, the reporter construct contained a large fragment of CYP1A1 regulatory region and an intercation between SMRT and a transcription factor other than AhR can not be ruled out. Therefore, we cotransfected cells with the XRE-TK-CAT construct (Fig. 4A), that only contains 3MCresponsive sequences of the CYPIAl gene and SMRT cDNA. In untreated cells, the transfection of SMRT do not modified the level of reporter gene product compared to control cells without SMRT (Fig. 4C). The increase of CAT activity level observed with cells transfected with XRE-TK-CAT and exposed with 3MC (2.6-fold) was subsequently inhibited after cotransfection with SMRT cDNA.

In order to strengthen our hypothesis, we looked for a physical interaction between AhR and SMRT by conducting coimmunoprecipitation assays with cells exposed to 3MC alone or with RA. Western blot analysis showed a physical interaction between SMRT and AhR (Fig. 5) as previously described [9] [26]. Furthermore, the levels of AhR/SMRT complex were markedly higher $(+65 \%)$ when cells were exposed with both $3 \mathrm{MC}$ and RA as compared with 
those exposed with 3MC alone. In regard to our results we suggest that the corepressor SMRT interact with AhR as soon as it is released from RAR after the binding of RA.

To summarize, CYP1A1 expression can be regulated either positively or negatively by several factors [27] [28]. In this way, our results show that a compound that regulates CYP1A1 expression positively, such as RA, could become a repressor agent when used with another inducer such as an AhR ligand. We demonstrated, in this work, a new mechanism of CYP1A1 regulation with the decrease of the expression and the functionality of AhR by RA : RA treatment of Caco- 2 cells decreased AhR protein level and, on the other hand, repress the 3MC-induced CYP1A1 induction through a physical interaction SMRT/AhR. Retinoids and carotenoids are micronutrients that are considered as "broad, multi-mechanism anticarcinogens" since they alter cell proliferation, allow cell differentiation and enhance apoptosis [29]. Concerning intestinal cells, several studies have shown that retinoids could act as protectors against chemical carcinogenesis [30]. However, the mechanism(s) by which they prevent or delay chemical carcinogenesis still remain(s) unclear [31]. Our work suggests that the decrease of PAH-induced CYP1A1 expression by retinoids in Caco-2 cells could be involved, at least in part, in the chemopreventive action of retinoids. 


\section{ACKNOWLEDGMENTS}

We thank Pr. A. Iliadis for his guidance with statistical program (UPRES EA 3286, Faculté de Pharmacie, Marseille, France). We thank P. Tucker for reviewing the English text. We thank H. Scoma, B. Charvet and C. Sauze for their technical assistance. 


\section{REFERENCES}

[1] E. Tavan, C. Cayuela, J.M. Antoine, G. Trugnan, C. Chaugier, P. Cassand, Effects of dairy products on heterocyclic aromatic amine-induced rat colon carcinogenesis, Carcinogenesis 23 (2002) 477-483.

[2] F.J. Gonzalez, P. Fernandez-Salguero, The aryl hydrocarbon receptor. Studies using the AhR-null mice, Drug Metab. Dispos. 26 (1998) 1194-1198.

[3] D.R. Nelson, L. Koymans, T. Kamataki, J.J. Stegeman, R. Feyereisen, D.J. Waxman, M.R. Waterman, O. Gotoh, M.J. Coon, R.W. Estabrook, I.C. Gunsalus, D.W. Nerbert, P450 superfamily: update on new sequences, gene mapping, accession numbers and nomenclature, Pharmacogenetics 6 (1996) 1-42.

[4] R.J. Fontana, K.S. Lown, M.F. Paine, L. Fortlage, J.S. Felton, M.G. Knize, A. Greenberg, P.B. Watkins, Effects of a chargrilled meat diet on expression of CYP3A, CYP1A and Pglycoprotein levels in healthy volunteers. Gastroenterology 117 (1999) 89-98.

[5] R.N. Hines, J.M. Mathis, C.S. Jacob, Identification of multiple regulatory elements on the human cytochrome P450IA1 gene, Carcinogenesis 9 (1988) 1599-1605.

[6] F Vecchini, M.C. Lenoir-Viale, C. Cathelineau, J. Magdalou, B.A. Bernard, B. Shroot, Presence of a retinoid responsive element in the promoter region of the human cytochrome P4501A1 gene, Biochem. Biophys. Res. Commun. 201 (1994) 1205-1212. 
[7] C. Delescluse, G. Lemaire, G. de Sousa, R. Rahmani, Is CYP1A1 induction always related to AHR signaling pathway? Toxicology 153 (2000) 73-82.

[8] S. Misiti, L. Schomburg, P.M. Yen, W.W. Chin, Expression and hormonal regulation of coactivator and corepressor genes, Endocrinology 139 (1998) 2493-2500.

[9] T.A. Nguyen, D. Hoivik, J.E. Lee, S. Safe, Interactions of nuclear receptor coactivator/corepressor proteins with the aryl hydrocarbon receptor complex. Arch. Biochem. Biophys. 367 (1999) 250-257.

[10] E.J. Park, D.J. Shroen, M. Yang, H. Li, J. Don Chen, SMRTe, a silencing mediator for retinoid and thyroid hormone receptors-extended isoform that is more related to the nuclear receptor corepressor, Proc. Natl. Acad. Sci. USA 96 (1999) 3519-3524.

[11] K. Jepsen, M.G. Rosenfeld, Biological roles and mechanistic actions of corepressor complexes, J. Cell Sci. 115 (2002) 689-698.

[12] M. Merchant, V. Morrison, M. Santostefano, S. Safe, Mechanism of action of aryl hydrocarbon receptor antagonists: inhibition of 2,3,7,8-tetrachlorodibenzo-p-dioxin-induced CYP1A1 gene expression, Arch. Biochem. Biophys. 298 (1992) 389-394.

[13] J.R. Petrulis, N.J. Bunce, Competitive behavior in the interactive toxicology of halogenated aromatic compounds, J. Biochem. Molecular Toxicology 14 (2000) 73-81. 
[14] J. Fogh, J.M. Fogh, T. Orfeo, 127 cultured human colon cell lines producing tumors in nude mice, Proc. Natl. Acad. Sci. USA 59 (1977) 221-226.

[15] N. Guigal, E. Seree, V. Bourgarel-Rey, Y. Barra, Induction of CYP1A1 by serum independent of AhR pathway, Biochem. Biophys. Res. Commun. 267 (2000) 572-576.

[16] M.D. Burke, S. Thompson, C.R. Elcombe, J. Halpert, T. Haaparanta, R.T. Mayer, Ethoxy-, pentoxy- and benzyloxyphenoxazones and homologues : a series of substrates to distinguish between different induced cytochromes P450, Biochem. Pharmacol. 34 (1985) $3337-3345$.

[17] S.W. Kennedy, S.P. Jones, L.J. Bastien, Efficient analysis of cytochrome P4501A catalytic activity, porphyrins, and total proteins in chicken embryo hepatocyte cultures with a fluorescence plate reader, Anal. Biochem. 226 (1995) 362-370.

[18] M.M. Bradford, A rapid and sensitive method for the quantitation of microgram quantitative of protein utilizing the principle of protein-dye binding, Anal. Biochem. 72 (1976) 248-254.

[19] J.D. Chen, R.M. Evans, A transcriptional co-repressor that interacts with nuclear hormone receptors, Nature 377 (1995) 454-457. 
[20] V. Bourgarel-Rey, S. Vallee, O. Rimet, S. Champion, D. Braguer, A. Desobry, C. Briand, Y. Barra, Involvement of nuclear factor kappaB in c-Myc induction by tubulin polymerization inhibitors, Mol. Pharmacol. 59 (2001) 1165-1170.

[21] P. Honkakoski, M. Negishi, Regulation of cytochrome P450 (CYP) genes by nuclear receptors, Biochem. J. 347 (2000) 321-337.

[22] M. Yoshida, M. Kijima, M. Akita, T. Beppu, Potent and specific inhibition of mammalian histone deacetylase both in vivo and in vitro by trichostatin A. J. Biol. Chem. 265 (1990) 17174-17179.

[23] L. Xu, T.S. Ruh, M.F. Ruh, Effect of the histone deacetylase inhibitor trichostatin A on the responsiveness of rat hepatocytes to dioxin, Biochem. Pharmacol. 53 (1997) 951-957.

[24] M.B. Kumar, G.H. Perdew, Nuclear receptor coactivator SRC-1 interacts with the Q-rich subdomain of the AhR and modulates its transactivation potential, Gene Expr. 8 (1999) 273286.

[25] A. Kobayashi, K. Numayama-Tsuruta, K. Sogawa, Y. Fujii-Kuriyama, CBP/p300 functions as a possible transcriptional coactivator of Ah receptor nuclear translocator (Arnt), J. Biochem. 122 (1997) 703-710.

[26] S.R. Rushing, M.S. Denison, The silencing mediator of retinoic acid and thyroid hormone receptors can interact with the aryl hydrocarbon $(\mathrm{Ah})$ receptor but fails to repress $\mathrm{Ah}$ receptor-dependent gene expression, Arch. Biochem. Biophys. 403 (2002) 189-201. 
[27] M.L. Withlaw, J. McGuire, D. Picard, J.A. Gustafsson, L. Poellinger, Heat shock protein hsp90 regulates dioxin receptor function in vivo, Proc. Natl. Acad. Sci. USA 92 (1995) $4437-$ 4441.

[28] Q. Ma, J.P. Whitlock, A novel cytoplasmic protein that interacts with the Ah receptor, contains tetratricopeptide repeat motifs, and augments the transcriptional response to $2,3,7,8$ tetrachlorodibenzo-p-dioxin, J. Biol. Chem. 272 (1997) 8878-8884.

[29] K. Krishnan, M.T. Ruffin IV, D.E. Brenner, Chemoprevention for colorectal cancer, Crit. Rev. Oncol. Hematol. 33 (2000) 199-219.

[30] S. Maziere, P. Cassand, J.F. Narbonne, K. Meflah, Vitamin A and apoptosis in colonic tumor cells, Int. J. Vitam. Nutr. Res. 67 (1997) 237-241.

[31] D.A. Ross, P. Kish, K.M. Muraszko, M. Blaivas, M. Strawderman, Effect of dietary vitamin A or $\mathrm{N}$-acetylcysteine on ethylnitrosourea-induced rat gliomas, J. Neurooncol. 40 (1998) 29-38. 
Fig. 1. Effects of 3MC and/or RA treatments on CYP1A1 expression in Caco-2 cell line. Cells were treated with : $0.1 \%$ DMSO as control (C), or $1 \mu \mathrm{M}$ RA (RA), or $10 \mu \mathrm{M} 3 \mathrm{MC}$ (3MC), or $10 \mu \mathrm{M} 3 \mathrm{MC}$ and $1 \mu \mathrm{M}$ RA (3MC+RA). A: EROD activity. Results are determined as mean \pm SEM $(\mathrm{n}=12)(* * *, p<0.001)$. B: Real time RT-PCR analysis of CYP1A1 mRNA expression. Results are determined as mean \pm SEM $(\mathrm{n}=6)(* * *, p<0.001)$. C: Determination of CYP1A1 promoter activity. Results are determined as mean $\pm \operatorname{SEM}(\mathrm{n}=8)(* *, p<0.01)$. All the results are expressed as percentage of control.

Fig. 2. Effect of $3 \mathrm{MC}$ and/or RA treatments on AhR total protein levels, evaluated by Western blot analysis. Blots are representative of three independent experiments. REL: relative expression level of AhR protein normalized to actin. Cells were treated as described in Fig. 1.

Fig. 3. Effects of $3 \mathrm{MC}$ and/or RA treatments with or without 300nM TSA on CYP1A1 mRNA expression, evaluated by real time RT-PCR. Results are determined as mean \pm SEM $(n=4)$.

Fig. 4. Modulation of CYP1A1 promoter activity in Caco-2 cells by the corepressor SMRT. A: pRNH25c and XRE-TK-CAT constructs are schematically displayed as well as the location of XRE sites within the regulatory region of the CYPIAl gene. B: Cotransfection with pRNH25c and SMRT cDNA. At the top: Control cells were treated with $0.1 \%$ DMSO; results are determined as mean \pm SEM $(n=4)$ then expressed as percentage of control. At the bottom: Increase of SMRT transfection correlates with the decrease of 3MC-induced CAT activity. Results are expressed as 3MC-treated cells/untreated cells ratio (mean \pm SEM, $n=4$ ), $(* * *, p<0.001)$. C: Cotransfection with XRE-TK-CAT and SMRT cDNA. Treatment with 
$0.1 \%$ DMSO as control (C), or $10 \mu \mathrm{M} 3 \mathrm{MC}(3 \mathrm{MC})$. Results are determined as mean $\pm \mathrm{SEM}$ $(n=4)$ then expressed as percentage of control.

Fig. 5. Physical interaction of $A h R$ and $S M R T$ evaluated by coimmunoprecipitation analysis in Caco-2 cells. Cells transfected with SMRT $(2 \mu \mathrm{g})$ were used as positive control The nuclear extracts were precipitated by anti-SMRT antibodies. The immunoprecipitated complexes were analyzed for AhR proteins by Western blotting. Blots are representative of three independent experiments. 
A

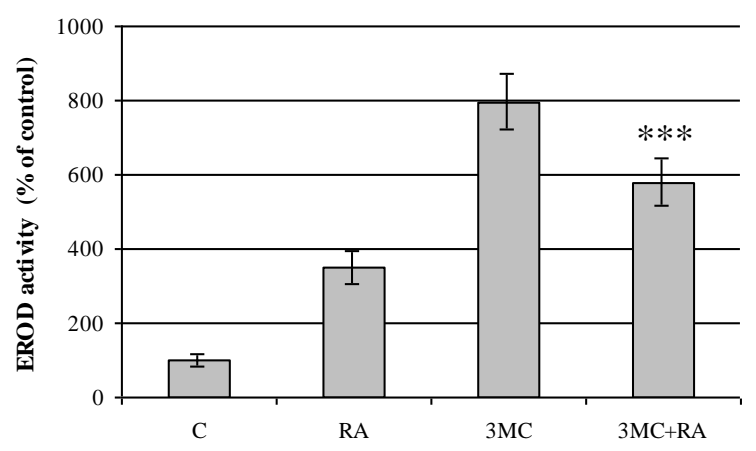

B

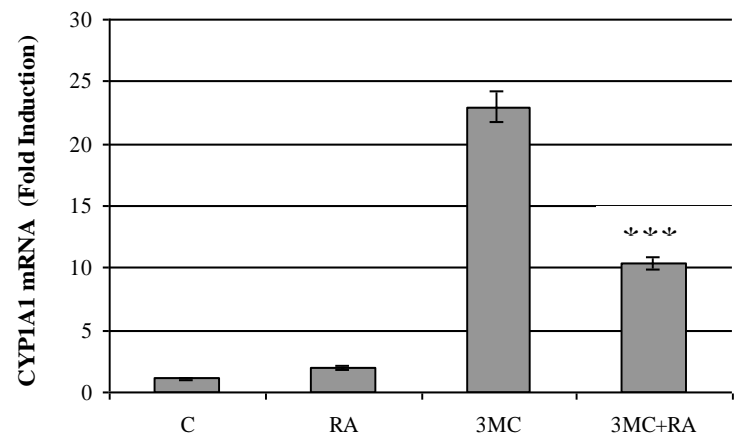

C

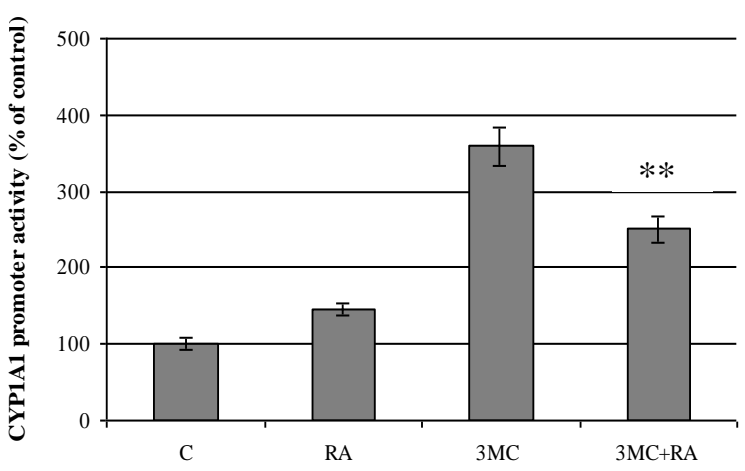

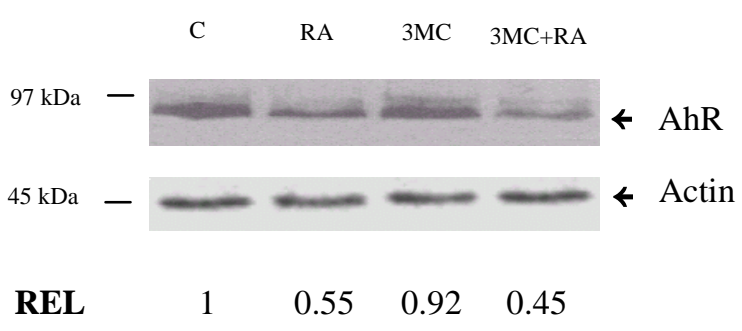

Figure 2

Figure 1

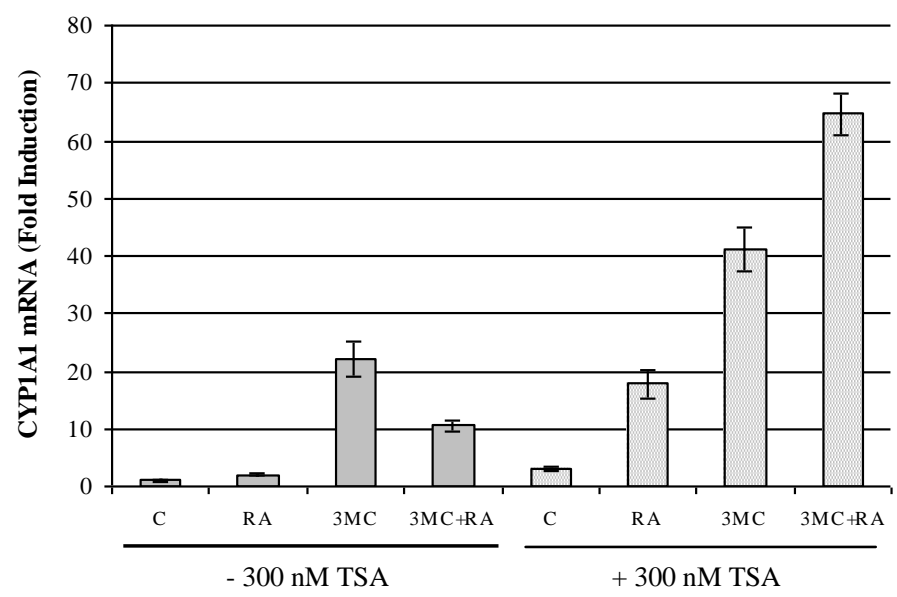

Figure 3 
A

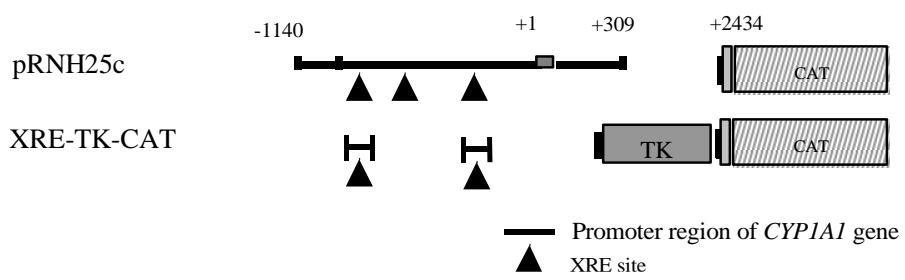

B
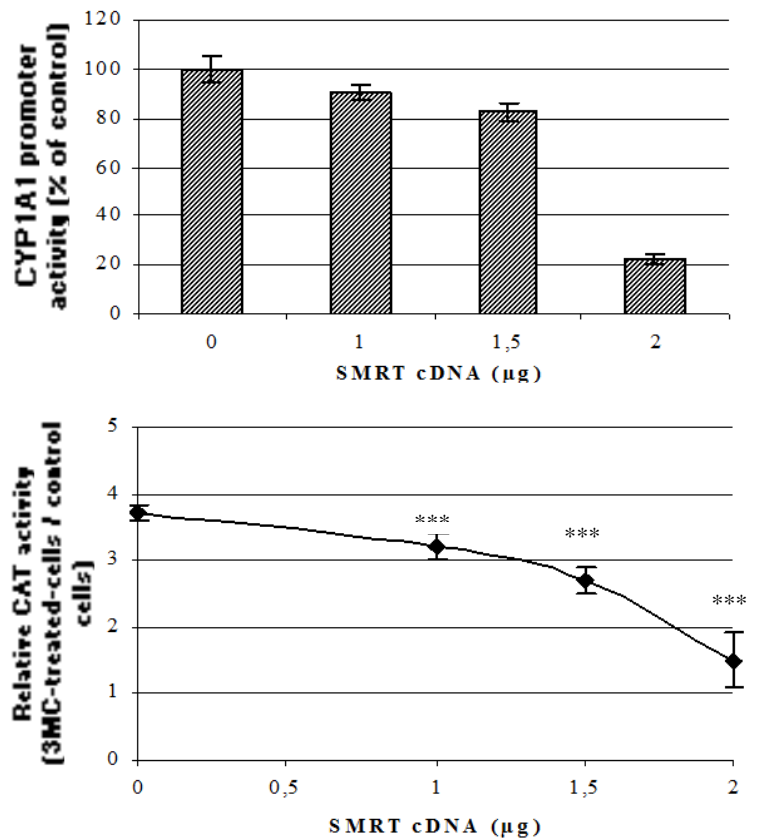

C
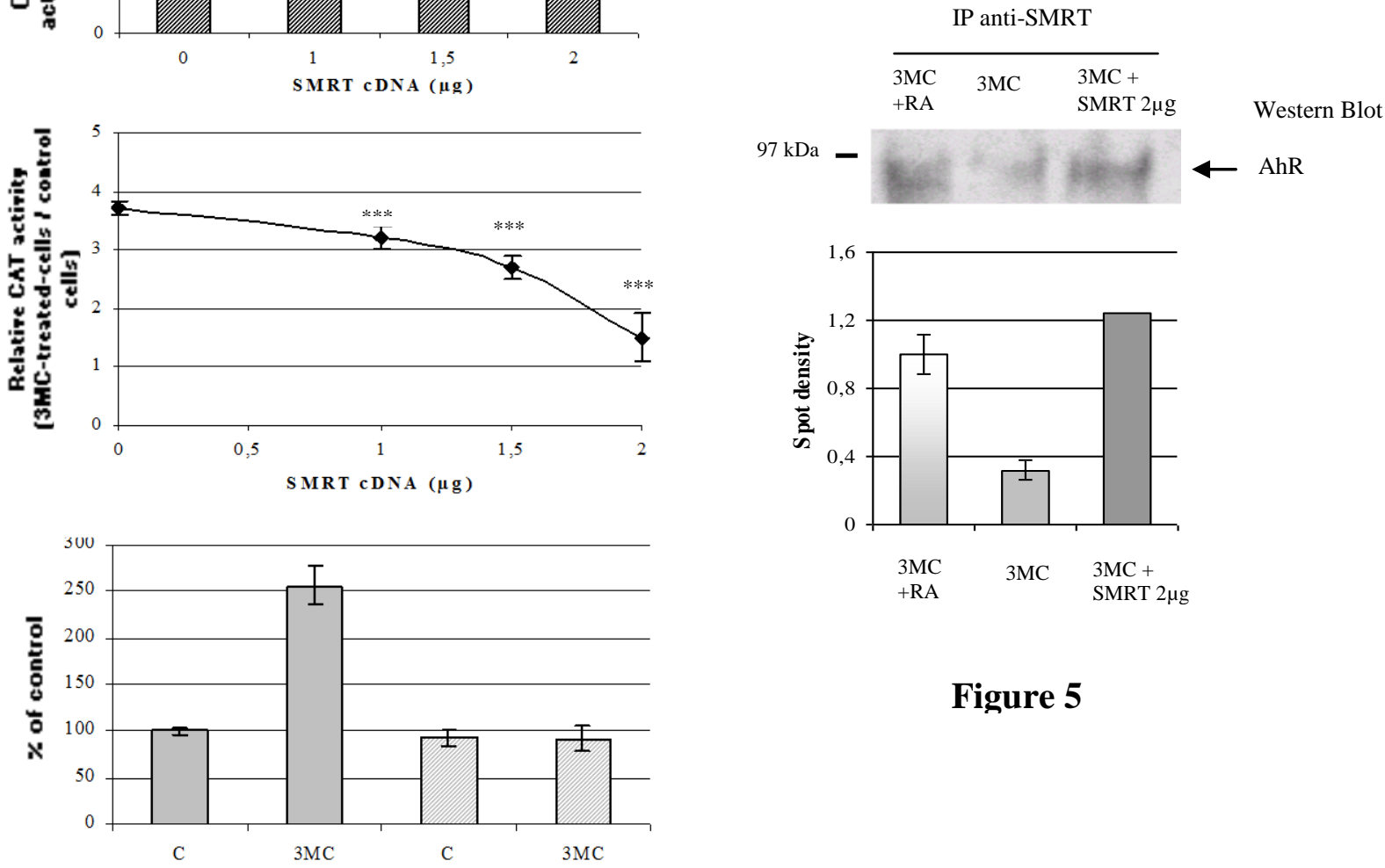

Figure 5

$\begin{array}{lllll}\text { XRE-TK-CAT } & + & + & + & + \\ \text { SMRT 2 } 2 \mu \mathrm{g} & - & - & + & +\end{array}$

Figure 4 